\title{
Role of BMS and Infrastructure in Crude Death Rate and Infant Mortality Rate
}

Abdul Basit ${ }^{1 *}$, Ishaque Ahmed Ansari² and Anam Riaz ${ }^{1}$

${ }^{1}$ S\&DWH Department, State Bank of Pakistan, Pakistan

${ }^{2}$ Research Scholar, NCBA\&E Lahore, Pakistan

\begin{abstract}
The aim of the study is to investigate the relationship of infrastructure of health sector and basic medical staff with the IMR and CDR respectively. Another purpose of doing this study is to describe the historical trend of infrastructure in Health sector and Basic Medical Staff (BMS). CGR and Year on Year (YoY) \% change of BMS and infrastructure shows that there is downward trend after the period 1995-96. The results of one way ANOVA shows that, each decade has different growth in infrastructure and basic medical staff. Similarly regression analysis shows that there is linear relationship among the IMR, CDR, basic medical infrastructure and BMS. The finding of the study indicates that basic infrastructure and basic medical staff is playing an important role in reducing the CDR and IMR of Pakistan. Infrastructure is playing significant role in the decreasing trend of CDR and IMR as compare to the BMS. This indicates that government of Pakistan needs to increase the budget for the infrasture of health sector.
\end{abstract}

Keywords: Crude Death Rate (CDR); Infant Mortality Rate (IMR); ANOVA; Compound Growth Rate (CMR)

\section{Introduction}

Researchers stated that an economy has three main pillars like agriculture sector, services sector and industrial sector. Economists and scholars state that there are three sectors of economy. Human capital is playing the role of backbone an economy. Health and education sector is the backbone of the performance of human capital.

Man Power or Labour force of a country is playing significant role in the performance of the agriculture and industrial sector. Healthy and educated employees of an industry are the source for growth of that industry.

Man Power also has the significant impact in agriculture and services sector of economy. The researchers and economist state that human capital is the major asset for the development of the country.

In LDCs, social welfare sector contains the minimum shares in the budget of country. As well as Govt. build the plans for the social welfare sectors on quarterly basis in developed countries. Govt. of the LDCs does not have the enough money/expense/budget for the social welfare as compare to the defence budget.

Social welfare facilities in developing countries are performing well as compare to less developed countries. Medical facilities for the public in developed countries are in better situation than the developing countries.

Health and education sector is playing a progressive role to improve the performance of human capital. The findings of the study will describes the performance of BMS and infrastructure of the Health sector.

Literature review of this study is presented in chapter 2, chapter 3 describes the research methodology. Data analysis and graphs are presented in chapter 4 and chapter 5 comprise the results, interpretation and conclusion

\section{Review of Literature}

Researchers and World Health Organization (WHO) stated that health sector of a country is the spine of the human capital. The introduction and importance of the health indicators and health sector facilities has been studied.
Akram and Jahangir [1] carried out a study in rural and urban areas of Pakistan with reference to the Govt. expense on health facilities. They apply the BIA III-steps methodology. The finding of the study is that Govt. budget for the health sector performing regressive role in rural areas. Doeksen and Schott [2] studied the impact of health sector to the economic growth of the country. They developed the relationship between the growth of economy and income of health services on the basis of rural data of Atoka. Basic infrastructure of health and other services has been used in their study. Gupta et al. [3] used BIA methodology for the data of 118 developing countries. They end up with the conclusion that developing countries increase their social facilities as public spending on health and education. Hamid et al. [4] apply the BIA methodology in different dimensions of social welfare. They collect the data on social welfare from fifty six countries. Hasan [5] carried out the study to identify the association between human capital and economic growth or development. He found the direct relationship between economic expenditure and social welfare indicators and also found that it has positive impact on the economic growth. Jude et al. [6] found the relationship of literacy rate and expense on health. They also found the link between expectancy of life and expense on health. They studied in both dynamics; long run and short run. The conclusion of the study is; Govt. needs to increase the budget for the social welfare to recover the health status. Nigel et al. [7] found that social and demographic factors of the parent affect the mortality of infants. These factors may be living areas, age of parents, literacy and health of parents. These are the major findings of their study. Rasmus et al. [8] found the affecting factors and reasons related to the government expenditure for social welfare. They also describe importance of social

*Corresponding author: Abdul Basit, S\&DWH Department, State Bank of Pakistan, Pakistan, Tel: 0092-333-4859346; E-mail: basit_ravian917@hotmail.com

Received December 15, 2015; Accepted January 20, 2016; Published January 27,2016

Citation: Basit A, Ansari IA, Riaz A (2016) Role of BMS and Infrastructure in Crude Death Rate and Infant Mortality Rate J Biom Biostat 7: 274 doi:10.4172/21556180.1000274

Copyright: (c) 2016 Basit A, et al. This is an open-access article distributed under the terms of the Creative Commons Attribution License, which permits unrestricted use, distribution, and reproduction in any medium, provided the original author and source are credited. 
welfare sector for LDCs. They found the important factors which are helpful to reduce the poverty. These factors are investment in human capital and distribution of the growth.

Razzak et al. [9] discuss the services related to the emergency in LDCs. For the study, data of twenty two rural and urban areas of Pakistan has been used. They conclude that in health system analysis, emergency care services should be element of health systems. Toor and Butt [10] studied the importance of socio-economic factors in the health sector of Pakistan. They described that in public sector spending; spending on healthcare facilities is most affecting factor for the improvement of Health sector of the country. Wang [11] studied the social factors related to child mortality. He also studied the Govt. expense on social welfare of sixty developing countries. In his study, he especially includes the Govt. expense on vaccination and health care centers for the children [12-14].

\section{Research Methodology}

Research methodology of the study is based on preparation of the variables, YoY growth rate, compound growth rate, ANOVA and simple linear regression.

\section{Variables}

In this study different variables have been used related to the health sector of Pakistan. These are infrastructure (INF), basic medical staff(BMS), IMR and CDR. Infrastructure of the health sector is stand on dispensaries, hospitals, Basic Health Units(BHU), rural health centers, TB centers and Maternity and Child Health Centres. INF is based on the aggregation of all the institutions of health sector. BMS is stand on the registered dentists, registered doctors, mid-wives, nurses and lady health visitors [15-17].

\section{Growth rate}

Growth rate is a \% change of studying period with reference to the previous period. Growth rate shows the decreasing or increasing trend of the studying variable. Growth rate is a simple tool to check the behavior of data. It provides the \%change between current and reference period.

\section{One way ANOVA}

One way ANOVA is used for testing the variability among the groups and it is also used for testing the comparison of averages of groups. For the comparison of the decade's growth in INF and BMS, One-way ANOVA has been used.

There are four decades which are considered in the study. For the INF, 1st group is based on the period of $1971-1980$, second group 1981 - 1990, third group is based on the period $1991-2000$ and fourth group is based on the period of $2001-2010$. For the BMS, $1^{\text {st }}$ group based on the period of $1974-1980$, second group $1981-1990$, third group is based on the period $1991-2000$ and fourth group is based on the period of $2001-2010$ [18,19].

\section{Health indicators}

WHO state different health indicators, which show the behavior of the health facilities. These indicators are same for all countries but the figures vary from one country to another country.

By the end of year 2012, these indicators of Pakistan are IMR (69.0\%), CDR (7.2\%) and CBR (27.20\%).

\section{Simple linear regression}

Linear Regression shows the relationship of endogenous and exogenous variables. Linear line has been developed for the describing the relationship of endogenous variables CDR and IMR with the exogenous variables INF and BMS.

$$
\begin{aligned}
& C D R=\alpha_{1}+\beta_{1} * \text { inf }+\gamma_{1} * B M S+\varepsilon \\
& I M R=\alpha_{2}+\beta_{2}{ }^{*} \text { inf }+\gamma_{2}{ }^{*} B M S+\varepsilon
\end{aligned}
$$

\section{Data Analysis}

Descriptive analysis has been performed to attain the objectives of the study. Compound Growth rate, ANOVA and Regression analysis performed for the variables which are under study.

\section{Growth rate}

YOY \%change of BMS and INF has been calculated. After the year 1996 , YOY \%change of INF shows the decreasing trend. For the period $1996-2010$, \%change is near to zero but it is still positive. There is high fluctuation during the period 1972 to 1995 , but these fluctuations are in positive way (Figure 1).

YOY \%change of BMS is showing declining trend but it is positive growth. For the period $1995-2010$, it is near to 5\%. The historical trend of BMS and INF shows that Govt. expense on health sector is declining during the period 1984-2010 (Figure 2).

\section{Compound growth rate}

Compound Growth rate of infrastructure and BMS is given below (Table 1).

The compound growth(CG) of infrastructure is $4.8 \%, 5.6 \%, 1.2 \%$ and $0.4 \%$ during the period 1971-1980, $1981-1990,1991-2000$ and $2001-2010$ respectively. The CG of basic medical staff is $16.5,13.0 \%$, $5.3 \%$ and $4.6 \%$ during the period 1970-1980, 1981 - 1990, 1991 2000 and $2001-2010$, respectively. This indicates that Government spending on infrastructure and basic medical staff in health sector is decreasing (Figure 3).

\section{One-way ANOVA}

ANOVA technique has been used for testing the average performance of INF and BMS during the four decades. Four groups are considered, 1st group consist on the period 1971 - 1980, second group contains the period 1981 - 1990, third group contains the period 1991 - 2000 and fourth group consist on $2001-2010$ (Table 2).

Above ANOVA table shows the significance of last four decades of INF. The significance value is less than $5 \%$ and it shows that, on average, not all the decades have same progress (Table 3 ).

Above ANOVA of BMS shows that all the decades have different performance. P-value is 0.000 which shows that not all the decades have equal means. The result of ANOVA Tables 4 and 5 support the finding of the decade percentage change.

\section{Historic trend of health indicators}

In this study CBR, CDR and IMR have been studied. These are the main indicators of health sector of any country. The declining trend of IMR and CDR shows that health sector is performing positively. In developing countries IMR and CDR is higher than the developed countries. The unavailability of BMS and INF are the main factors of high IMR and CDR. 
Citation: Basit A, Ansari IA, Riaz A (2016) Role of BMS and Infrastructure in Crude Death Rate and Infant Mortality Rate. J Biom Biostat 7: 274. doi:10.4172/2155-6180.1000274



Figure 1: Trend in infrastructure in health sector.



Figure 2: Trend in BMS in health sector.

There is a declining trend in IMR and CDR of Pakistan. CDR for the last decade is nearly 8 per thousand. Similarly IMR for the last decade is approximately 80 per thousand. The declining trend of IMR and CDR shows that BMS and INF performing well in Pakistan (Figure 4).

\section{Correlation and regression analysis}

This study is carried out to find the relationship among INF, BMS and CDR. The 2nd major purpose of the study is to point out the relationship among BMS, INF and IMR. The correlation matrix of INF, BMS and CDR is explained in Table 4.

Correlation between CDR and BMS is -0.959 which indicates the negative relationship of both variables. Correlation coefficient of CDR and INF is -0.898 which also indicates the inverse relationship. The significance value is less than $5 \%$ and it indicates the high significant relationship.
The correlation matrix of INF, BMS and IMR is explained in Table 5.

The correlation coefficient of INF and IMR is - 0.921 and showing inverse relationship. The $\mathrm{P}$-value is less than the $5 \%$ level of significance and it shows strong relationship between INF and IMR.

The correlation coefficient of BMS and IMR is -0.929 and showing inverse relationship. The $\mathrm{P}$-value is less than the $5 \%$ level of significance and it shows strong relationship between BMS and IMR (Figure 5).

Regression line for CDR: Ordinary Least Square has been used for estimating model coefficient (Table 6). Linear regression for the CDR is:

$$
\begin{aligned}
& C D R=\alpha_{1}+\beta_{1}^{*} I N F+\gamma_{1}^{*} B M S+\varepsilon \\
& \mathrm{CDR}=13.612-0.214 * \text { INF. }-0.013 * \text { BMS. }
\end{aligned}
$$

The constant of model 1 is 13.612 and it has the significance in the 
Citation: Basit A, Ansari IA, Riaz A (2016) Role of BMS and Infrastructure in Crude Death Rate and Infant Mortality Rate. J Biom Biostat 7: 274. doi:10.4172/2155-6180.1000274

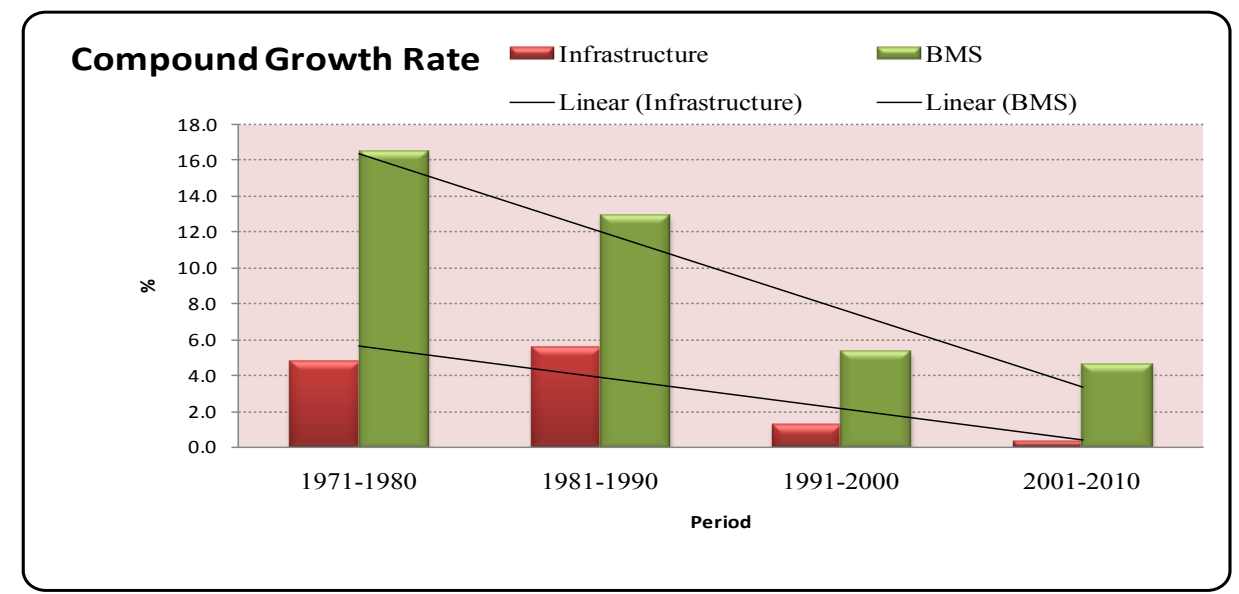

Figure 3: Compound growth rate of infrastructure and BMS.

\section{Infant Mortality Rate and Crude Death Rate}

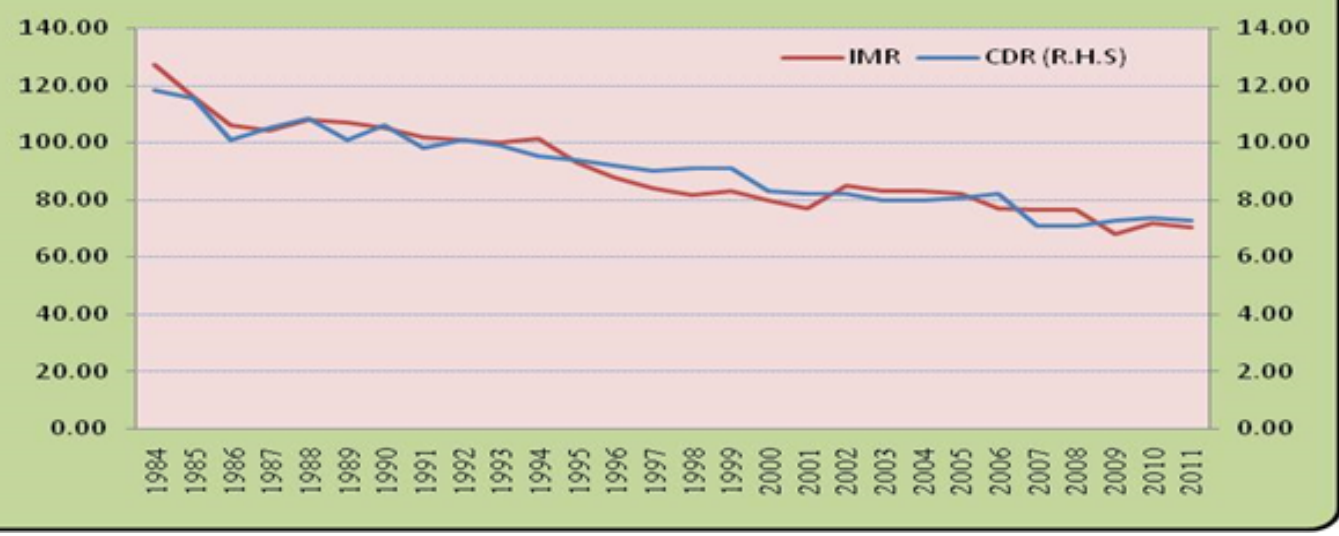

Figure 4: IMR and CDR of Pakistan.

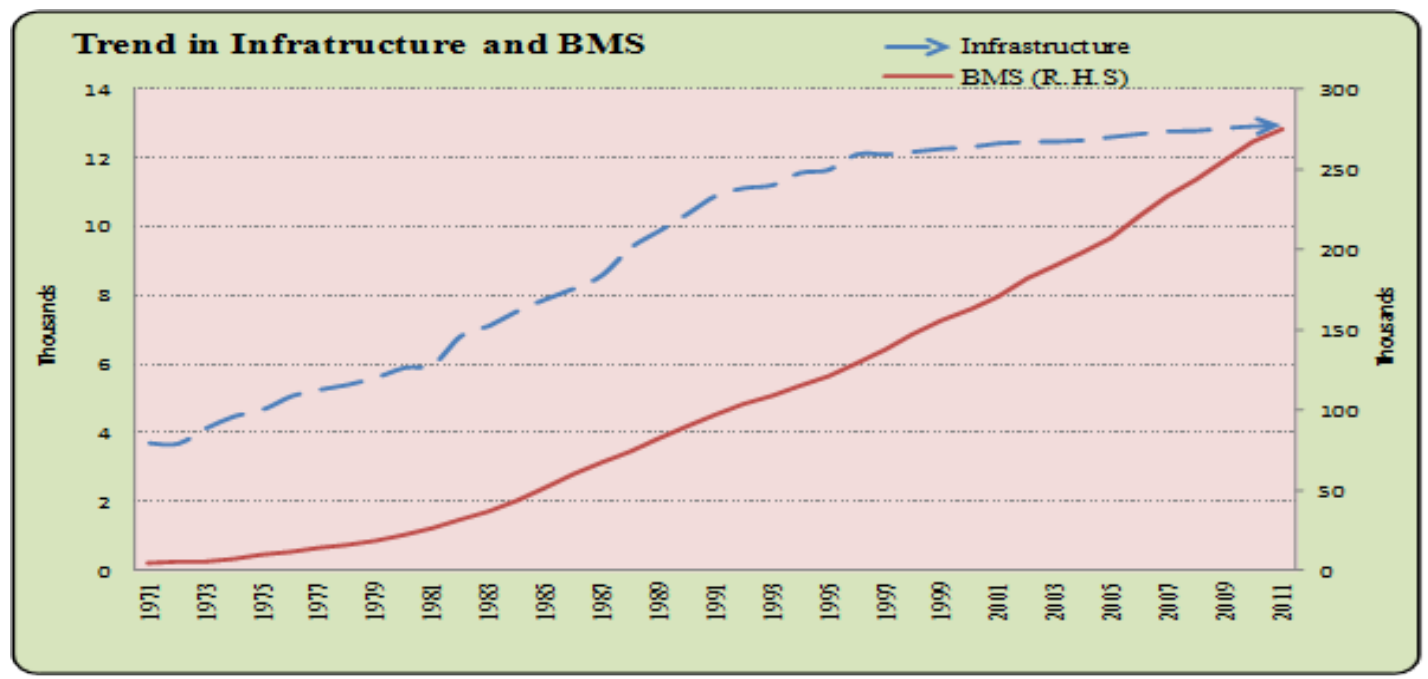

Figure 5: Trend in BMS and INF. 
Citation: Basit A, Ansari IA, Riaz A (2016) Role of BMS and Infrastructure in Crude Death Rate and Infant Mortality Rate. J Biom Biostat 7: 274 doi:10.4172/2155-6180.1000274

Page 5 of 6

model. The signs of the INF and BMS coefficients are negative which shows the indirect relationship with the CDR (Table 7).

Above results shows the significance of model 1. In the above table $\mathrm{P}-$ Value shows that BMS and INF are significant in the equation 1.

Linear regression of IMR: This study is carried out to explain the linear relationship of BMS, INF and IMR. Pearson Coefficient of Correlation explains the indirect or negative association among BMS and IMR also between INF and IMR (Table 8).

$$
\begin{aligned}
& I M R=\alpha_{2}+\beta_{2} * I N F+\gamma_{2} * B M S+\varepsilon \\
& I M R=155.918-4.218 * I N F-0.114{ }^{*} \text { BMS }
\end{aligned}
$$

The constant of the eq. 2 is 155.918 and it has the significance in the model. The signs of the INF and BMS coefficients are negative which shows the indirect relationship with the IMR (Table 9).

Table 9 shows the significance of the eq. 2 and it is significant at $5 \%$. This shows that BMS and INF are significant in the equation 2.

\begin{tabular}{|l|l|l|}
\hline Decade & Infrastructure & BMS \\
\hline $1971-1980$ & 4.8 & 16.5 \\
\hline $1981-1990$ & 5.6 & 13.0 \\
\hline $1991-2000$ & 1.2 & 5.3 \\
\hline $2001-2010$ & 0.4 & 4.6 \\
\hline
\end{tabular}

Table 1: CGR of infrastructure and BMS.

\begin{tabular}{|l|l|l|l|l|l|}
\hline & SS & d.f & MSE & F & P-Value \\
\hline Between Groups & 387.02 & 3 & 129.01 & 179.91 & 0.000 \\
\hline Within Groups & 25.81 & 36 & 0.72 & & \\
\hline Total & 412.84 & 39 & & & \\
\hline
\end{tabular}

Table 2: ANOVA for basic INF.

\begin{tabular}{|l|l|l|l|l|l|}
\hline & SS & d.f & MSE & F & P-Value \\
\hline Between Groups & 241223.5 & 3 & 80407.83 & 153.86 & 0.000 \\
\hline Within Groups & 18814.32 & 36 & 522.62 & & \\
\hline Total & 260037.8 & 39 & & & \\
\hline
\end{tabular}

Table 3: ANOVA for basic medical staff.

\begin{tabular}{|l|l|l|l|l|}
\hline Correlations & & CDR & Inf & BMS \\
\hline \multirow{3}{*}{ Pearson Correlation } & CDR & 1 & -0.898 & -0.959 \\
\cline { 2 - 5 } & P-Value & 1 & 0.000 & 0.000 \\
\cline { 2 - 5 } & N & 28 & 28 & 28 \\
\hline
\end{tabular}

\begin{tabular}{|c|c|c|c|c|}
\hline \multicolumn{5}{|l|}{ Correlations } \\
\hline & & IMR & Inf & BMS \\
\hline \multirow[b]{3}{*}{ Pearson Correlation } & IMR & 1 & -0.921 & -0.929 \\
\hline & P-Value & 1 & 0 & 0 \\
\hline & $\mathrm{N}$ & 28 & 28 & 28 \\
\hline
\end{tabular}

Table 4: Correlation of BMS, INF and CDR.

Table 5: Correlation of BMS, INF and IMR.

\begin{tabular}{|l|l|l|l|l|}
\hline \multicolumn{3}{|l|}{ Coefficients } & t & P-Value \\
\hline & B & S.E & & \\
\hline Intercept & 13.612 & 0.693 & 19.639 & 0.000 \\
\hline INF & -0.214 & 0.081 & -2.633 & 0.014 \\
\hline BMS & -0.013 & 0.002 & -7.206 & 0.000 \\
\hline
\end{tabular}

Table 6: Regression summary of BMS, INF and CDR.

\begin{tabular}{|l|l|l|l|l|l|}
\hline & SS & d.f & MSE & F & P-Value \\
\hline Regression & 45.349 & 2 & 22.675 & 187.859 & 0.000 \\
\hline Residual & 3.018 & 25 & 0.121 & & \\
\hline Total & 48.367 & 27 & & & \\
\hline
\end{tabular}

Table 7: ANOVA for model 1

\begin{tabular}{|l|l|l|l|l|}
\hline \multicolumn{3}{|l|}{ Coefficients } & T & P-Value \\
\hline & B & S.E & & \\
\hline Intercept & 155.918 & 9.077 & 17.178 & 0.000 \\
\hline Inf & -4.218 & 1.066 & -3.959 & 0.001 \\
\hline BMS & -0.114 & 0.026 & -4.474 & 0.000 \\
\hline
\end{tabular}

Table 8: Regression of IMR, INF and BMS.

\begin{tabular}{|l|l|l|l|l|l|}
\hline & SS & d.f & MSE & F & P-Value \\
\hline Regression & 5629.515 & 2 & 2814.757 & 135.991 & 0.000 \\
\hline Residual & 517.454 & 25 & 20.698 & & \\
\hline Total & 6146.969 & 27 & & & \\
\hline
\end{tabular}

Table 9: ANOVA Regression equation 2.

\section{Summary}

YOY \%change of BMS and INF is decreasing as compared to the \%change before 1995 to 1996 . Compound growth rate of infrastructure for decades $1991-2000$ and $2001-10$ is lesser than the growth of decades 1971-1980 and1981 - 1990. Similarly compound growth rate of Basic Medical Staff is showing the declining trend. Growth rate for $1991-2000$ and $2001-2010$ showing the less growth as compare to the period 1971-1980 and 1981 - 90 ANOVA check the equality of the average performance of BMS and INF in each decade. The average performance of BMS and INF are different in each decade. IMR and CDR are major health indicators of a country. The declining trend of these indictors is a positive for Government and public of Pakistan. The correlation of CDR and INF is -0.898 , CDR and BMS is -0.959 . It indicates the strong negative relationship. The correlation coefficient of IMR and INF is - 0.921 , IMR and BMS is -0.929 . It also indicates the strong negative relationship. The two regression line (eq. 1 and eq. 2 ) explains the linear relationship among the variables. The coefficients of BMS and INF in both equations are negative which indicates that IMR and CDR will decrease if there is an increase in health facilities.

\section{Conclusion}

From the above discussion, we conclude that Govt. expenditure on social welfare is increasing but the nominal expense is remaining same. Govt. expense on BMS and development of INF in health sector has decreasing trend since 1995. As IMR and CDR showing downward trend but still IMR and CDR are higher in Pakistan as compare to the other countries. Simple linear regression indicates that, increase in BMS and INF will decrease the IMR and CDR of Pakistan. There is a need to construct the better infrastructure in rural as well as urban level to decrease the IMR and CDR in Pakistan. There is also needs to educated the people and produced more LHVs, Nurses, specialized doctors, and mid-wives.

\section{Reference}

1. Akram M, Khan FJ (2007) Health Care Services and Government Spending in Pakistan.

2. Doeksen GA, Schott V (2003) Economic Importance of Health-care Sector in rural economy. Rural Remote Health 3: 135.

3. Gupta S, Clements B, Tiongson E (1998) Public Spending on Human Development Economic Policy and Equity Finance and Development 35: 10-13. 
Citation: Basit A, Ansari IA, Riaz A (2016) Role of BMS and Infrastructure in Crude Death Rate and Infant Mortality Rate. J Biom Biostat 7: 274. doi:10.4172/2155-6180.1000274

4. Hamid R, Davoodi R, Tiongson E, Sawitree S, Asawnuchit (2003) How Useful Are Benefit Incidence Analyses of Public Education and Health Spending.

5. Hasan MA. Role of human capital in economic development: some myths and realities in ESCAP. Development planning in a Market Economy (United Nations publication, Sales No. E.02.II.F.24).

6. Jude U, Riman HB, Edu EB (2010) Health Care Expenditure in Nigeria: Does the level of Government Spending Really Matter?.

7. Nigel P, Wallenstein S, John L, Susser M (1982) Social Class Indicators And Mortality In Low Birth Weight Infants. American Journal of Epidemiology 116: 364-375.

8. Rasmus H, Simler K, Tarp F (2001) Public Spending and Poverty in Mozambique. International Food Policy Research Institute.

9. Razzak JA, Hyder A, Akhter T, Khan M, Khan UR (2008) Assessing emergency medical care in low income countries: A pilot study from Pakistan.

10. Toor IA, Butt MS (2005) Determinants of Health Expenditure in Pakistan. Pakistan Economic and Social Review 43: 133-150.
11. Wang $L$ (2002) Health outcomes in poor countries and policy options: empirical findings from demographic and health surveys. World Bank Working Paper 2831.

12. Fisher RA (1925) Theory of Statistical Estimation Proc. Cambridge phil Soc 22: $700-725$

13. Legendre AM (1805) Nouvelles methodes pour la determination desorbites des cometes. Courcier. Paris Reprinted in 1959 by Dover, NewYork.

14. Feldstein M (1966) A Binary Variable Multiple Regression Method of Analyzing Factors affecting Peri-Natal Mortality and other outcomes of pregnancy. Journal of the Royal Statistical Society. Series A (General) 129: 61-73.

15. Ministry of Finance (2012) Economic Survey of Pakistan.

16. Gemmell N (1985) The Incidence of Government Expenditure and Redistribution in the United Kingdom. Economica New Series 52: 335-344.

17. State Bank of Pakistan (2010) Handbook of Statistics on Pakistan Economy.

18. World Health Organization Annual Report (2008) WHO Statistical Information System (WHOSIS).

19. World Health Organization Annual Report 2009. 